\title{
Editorial
}

Journal of Innate

Immunity

Published online: June 12, 2012

DOI: $\underline{10.1159 / 000339280}$

\section{Innate Immune Functions of Macrophages in Different Tissue Environments}

\author{
Siamon Gordon \\ Sir William Dunn School of Pathology, University of Oxford, Oxford, UK
}

Although the recognition, signaling and secretory responses of macrophages to innate immune stimuli have been extensively documented ex vivo and in vitro, we have limited knowledge of the role of the local microenvironment in modulating macrophage functions in situ. Tissue populations represent the vast majority of macrophages in the body, and display considerable heterogeneity in their specialised trophic and antimicrobial functions such as phagocytosis and cytotoxicity. Phenotypic antigen expression by resident, recruited and immunologically activated macrophages varies markedly with lympho-hemopoietic and non-lymphoid location, but the tissue factors responsible for extensive macrophage microheterogeneity and its functional significance remain obscure. This special issue features selected reviews dealing with this topic.

Whilst the local environment is a crucial determinant, Cortez-Retamozo et al. [1] draw attention to the distinct tropism and differential pathophysiological functions of newly recruited lineage precursors for macrophages and dendritic cells, responding to infectious, metabolic and neoplastic stimuli. Recent studies, elsewhere, by the Geissmann [2] and Merad [3] groups, indicate that Langerhans cells, microglia and perhaps other resident macrophages of adult mice originate from yolk sac precursors, raising the possibility of selective manipulation of cells of different origin.

\section{KARGER \\ Fax +4161306 1234 \\ E-Mail karger@karger.ch}

www.karger.com (c) 2012 S. Karger AG, Basel

$1662-811 X / 12 / 0046-0409 \$ 38.00 / 0$

Accessible online at:

www.karger.com/jin
Reviews by Gray and Cyster [4] and den Haan and Kraal [5] present the remarkable heterogeneity of macrophages in lymph nodes and spleen, respectively, at the interface between lymph, blood and the immune system. Subcapsular and marginal zone macrophages express unique pattern recognition receptors, interact with Band T-lymphocyte subpopulations, and bridge the innate and adaptive immune systems by presenting antigens and serving as portals to virus infection. The splenic red pulp provides a reservoir of macrophages [6] and plays a major role in iron homeostasis. As described by Ganz [7], iron from senescent erythrocytes that have been cleared in spleen and liver is recycled, a process regulated by the hepatocyte peptide hepcidin and the macrophage exporter ferroportin.

In the gut and gut-associated lymphoid tissue, as discussed by de Campos et al. [8], P2X7 purinergic receptors illustrate the importance of site-specific modulation of receptor function. These receptors are expressed heterogeneously, depending on their location, for example in mesenteric lymph nodes or the peritoneum, and display differential sensitivity in macrophages, lymphocytes and epithelium.

The anterior chamber of the eye is an immunologically privileged site. Bronkhorst and Jager [9] describe the inflammatory, macrophage-rich infiltrate in the highly malignant human uveal intra-ocular melanoma, associ- 
ated with monosomy of chromosome 3 and a poor prognosis.

Weidenbusch and Anders [10] report on the evolution of inflammation, repair and fibrosis, spatially and temporally, within injured tissues, in an attempt to restore local homeostasis. Once the macrophages accumulate at a particular site, they undergo further heterogeneity in response to unique local cues, as well as modulation by cytokines, host and microbial metabolites. Dasgupta and Keegan [11] delineate the dynamic evolution of alternative (IL-4/13-mediated) activation of macrophages in the lung during allergy and parasitic infection. Lee [12] reveals differential responses by discrete macrophage subsets to cigarette smoke in the pathogenesis of chronic obstructive pulmonary disease in humans.
Williams et al. [13] review the importance of macrophage heterogeneity within atherosclerotic lesions, relevant to plaque vulnerability and thrombus formation, the net result of monocyte recruitment, turnover and emigration, features perhaps amenable to therapy. Finally, Moghimi et al. [14] describe the rules and prospects of selective targeting of tissue macrophages, using various particulates optimised with regard to their physical properties, for delivery via different portals of entry.

The above articles indicate the clear need for further studies in this area. In spite of the explosive growth of microarray, proteomics and systems biology, we know little about the molecular determinants imposed by individual microenvironments, or the complex phenotype and functions of macrophages within human tissue, in health and disease.

\section{References}

1 Cortez-Retamozo V, Etzrodt M, Pittet MJ: Regulation of macrophage and dendritic cell responses by their lineage precursors. J Innate Immun 2012;4:411-423.

-2 Schulz C, Gomez Perdiguero E, Chorro L, Szabo-Rogers H, Cagnard N, Kierdorf K, Prinz M, Wu B, Jacobsen SE, Pollard JW, Frampton J, Liu KJ, Geissmann F: A lineage of myeloid cells independent of Myb and hematopoietic stem cells. Science 2012;336:8690.

-3 Ginhoux F, Greter M, Leboeuf M, Nandi S, See P, Gokhan S, Mehler MF, Conway SJ, Ng LG, Stanley ER, Samokhvalov IM, Merad M: Fate mapping analysis reveals that adult microglia derive from primitive macrophages. Science 2010;330:841-845.

$\checkmark 4$ Gray EE, Cyster JG: Lymph node macrophages. J Innate Immun 2012;4:424-436.

$>5$ den Haan JMM, Kraal G: Innate immune functions of macrophage subpopulations in the spleen. J Innate Immun 2012;4:437-445.
6 Swirski FK, Nahrendorf M, Etzrodt M, Wildgruber M, Cortez-Retamozo V, Panizzi P, Figueiredo JL, Kohler RH, Chudnovskiy A, Waterman P, Aikawa E, Mempel TR, Libby $\mathrm{P}$, Weissleder R, Pittet MJ: Identification of splenic reservoir monocytes and their deployment to inflammatory sites. Science 2009;325:612-616.

7 Ganz T: Macrophages and systemic iron homeostasis. J Innate Immun 2012;4:446453.

$>8$ de Campos NE, Marques-da-Silva C, Corrêa G, Castelo-Branco MTL, de Souza HSP, Coutinho-Silva R: Characterizing the presence and sensitivity of the $\mathrm{P} 2 \mathrm{X} 7$ receptor in different compartments of the gut. J Innate Immun 2012;4:529-541.

9 Bronkhorst IHG, Jager MJ: Uveal melanoma: the inflammatory microenvironment. J Innate Immun 2012;4:454-462.
10 Weidenbusch M, Anders HJ: Tissue microenvironments define and get reinforced by macrophage phenotypes in homeostasis or during inflammation, repair and fibrosis. J Innate Immun 2012;4:463-477.

11 Dasgupta P, Keegan AD: Contribution of alternatively activated macrophages to allergic lung inflammation: a tale of mice and men. J Innate Immun 2012;4:478-488.

12 Lee JS: Heterogeneity of lung mononuclear phagocytes in chronic obstructive pulmonary disease. J Innate Immun 2012;4:489497.

13 Williams HJ, Fisher EA, Greaves DR: Macrophage differentiation and function in atherosclerosis: opportunities for therapeutic intervention? J Innate Immun 2012;4:498508

14 Moghimi SM, Parhamifar L, Ahmadvand D, Wibroe PP, Andresen TL, Farhangrazi ZS, Hunter AC: Particulate systems for targeting of macrophages: basic and therapeutic concepts. J Innate Immun 2012;4:509-528. 